\title{
Aa. Vv., Le Français Préclassique
}

\section{Michele Mastroianni}

\section{(2) OpenEdition}

\section{Journals}

\section{Edizione digitale}

URL: http://journals.openedition.org/studifrancesi/3708

DOI: 10.4000/studifrancesi.3708

ISSN: 2421-5856

\section{Editore}

Rosenberg \& Sellier

\section{Edizione cartacea}

Data di pubblicazione: 1 décembre 2012

Paginazione: 559

ISSN: 0039-2944

\section{Notizia bibliografica digitale}

Michele Mastroianni, «Aa. Vv., Le Français Préclassique», Studi Francesi [Online], 168 (LVI | III) | 2012, online dal 30 novembre 2015, consultato il 07 mars 2021. URL: http://journals.openedition.org/ studifrancesi/3708 ; DOI: https://doi.org/10.4000/studifrancesi.3708

Questo documento è stato generato automaticamente il 7 mars 2021.

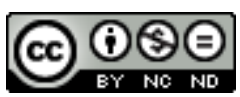

Studi Francesi è distribuita con Licenza Creative Commons Attribuzione - Non commerciale - Non opere derivate 4.0 Internazionale. 


\section{Aa. Vv., Le Français Préclassique}

Michele Mastroianni 


\section{NOTIZIA}

Le Français Préclassique, 1500-1650, vol. XIII, Paris, Champion, 2011, pp. 197.

1 Questo numero della rivista «Le Français Préclassique», del Centre d'Études lexicologiques et lexicographiques des $\mathrm{XVI}^{\mathrm{e}}$ et $\mathrm{XVII}{ }^{\mathrm{e}}$ siècles dell'Université Lumière-Lyon 2, studia campi semantici diversi della lingua del Cinquecento. Anzitutto abbiamo due saggi concernenti il vocabolario medico. Il primo di Jacqueline vons (Unifier ou expliquer des dénominations anatomiques multiples. L'exemple des noms des dents dans quelques traités d'anatomie $d u \quad \mathrm{XVI}^{e}$ siècle, pp.11-26) attraverso un'indagine sull'odontologia cinquecentesca mette in evidenza la circolazione di informazione da un autore all'altro e il tentativo di costituire un lessico ridotto e comune nell'area scientifica in questione. Il secondo di Michèle CLÉMENT (De l'anacronisme et du clitoris, pp. 27-45), studiando il termine clitoris riprende da un'angolatura lessicografica il problema dell'anacronismo, grazie a un accurato confronto di testi medici. Marthe PAQUANT (Le jargon de Rasse des Nœuds: «Abbuz» et «Chant Royal», pp.47-89), attraverso l'esame di due testi inediti di Rasse des Nœuds (chirurgo regio, m. nel 1588), qui trascritti, ne studia il lessico gergale. Particolarmente importante è il saggio di Marie Luce HONESTE (Le phénomène de rémanence et ses conséquences en sémantique lexicale à travers l'histoire du mot 'opinion', pp.91-113), in quanto lo studio della rémanence, ovvero della presenza di elementi costanti, nella storia del termine opinion, offre un utilissimo strumento di individuazione di aree teologiche cinquecentesche, a partire dall'uso del termine in questione nella polemica antiprotestante. Infine, Philippe SELOSSE (Le rondeau renaissant et son 'épistémè': syntaxe, sémantique et rime dans les rondeaux de Jean Bouchet et Clément Marot, pp.115-171), in un saggio ricco e ampio, chiarisce la natura dei principi strutturali propri dell'episteme del Cinquecento, per il tramite di uno studio dei meccanismi stilistici e linguistici del rondeau rinascimentale, in particolare attraverso l'esemplificazione dei testi di Bouchet e Marot. 